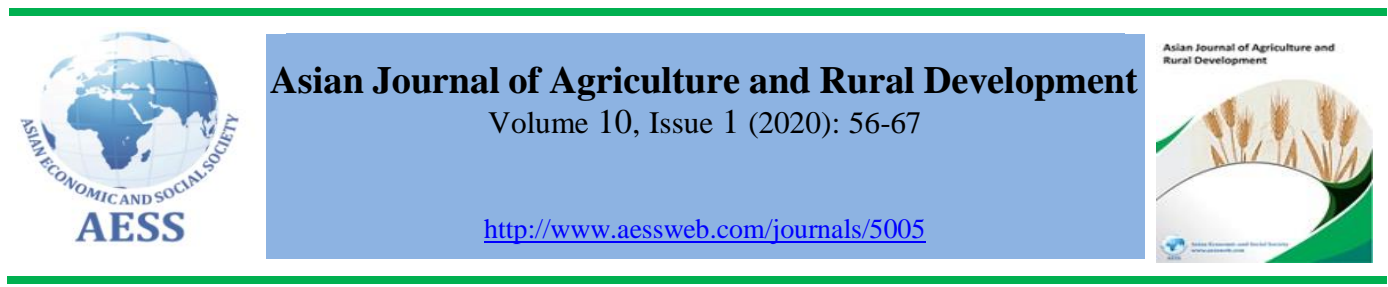

\title{
SUSCEPTIBILITY AND RESISTANT OF DIFFERENT HOST VARIETIES OF OIL PALM AND COCONUT PALM TOWARDS PEST, RHINOCEROS BEETLE (ORYCTES RHINOCEROS)
}

Izaitul Aida, I. $^{\text {a }}$

Mohd Rasdi, Z. ${ }^{\text {b }}$

Ismail, R., ${ }^{\mathrm{c}}$

Ismeazilla, M. B., ${ }^{\mathrm{d}}$

Mohd Faizol, K., ${ }^{\mathrm{d}}$

Muhammad Shakir, Z., ${ }^{\mathrm{d}}$

Nur Fakriyah, A., d
${ }^{\text {a }}$ Post graduate student; Faculty of Plantation and

Agrotechnology, Universiti Teknologi MARA, Shah Alam, Malaysia

b Associate Professor; Faculty of Plantation \&

Agrotechnology, Universiti Teknologi MARA Jasin, Melaka, Malaysia

${ }^{\mathrm{c}}$ Lecturer; Faculty of Plantation \& Agrotechnology,

Universiti Teknologi MARA Jasin, Melaka, Malaysia

${ }^{d}$ Post graduate student; Faculty of Plantation and

Agrotechnology, Universiti Teknologi MARA, Shah Alam, Malaysia

$\bowtie \underline{\text { dddpim@pahang.uitm.edu.my }}$ (Corresponding author)

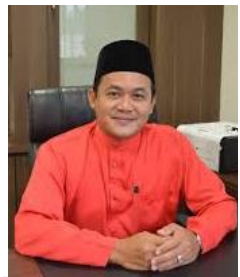

Corresponding author

Noor Shuhaina, S. M. ${ }^{d}$

ARTICLE HISTORY:

Received: 31-Aug-2019

Accepted: 20-Feb-2020

Online Available: 05-Mar2020

\section{Keywords:}

Susceptibility,

Resistant,

Oil palm,

Coconut palm,

Oryctes rhinoceros,

Pheromone

\begin{abstract}
In the current study, population dynamics of males, females, and total males and females of Rhinoceros Beetle (Oryctes rhinoceros), namely, DXP PPNJ 1 and DXP PPNJ 2, was evaluated in different host varieties of oil palms and coconut palms of Ladang Penyelidikan Segamat in Johor State of Malaysia. Ethyl 4-methyloctanote had been used as a pheromone aggregation in this study. The results clearly indicated that population dynamics of Oryctes Rhinoceros (total male and female) in oil palms and coconut palms has significant difference within the whole sampling period. Based on cumulative Oryctes Rhinoceros caught, varieties of DXP PPNJ 1 and DXP PPNJ 2 had significant effects on its male and female population. MYD inclined more towards the population of Oryctes Rhinoceros male, female and total male and female, giving more impacts, when ccompared with MRD and Tagnanan. Both crops of same species/family were not recommended for planting in that area, because it facees similar problems of direct Oryctes Rhinoceros attacks, obviously affecting the yield. Therefore, MRD and Tagnanan, considered to be a cross-variety, had been recommended to farmers. Instead of having higher yields, farmers have lesser chances of severe attacks by Oryctes Rhinoceros, within the same time period.
\end{abstract}

\section{Contribution/ Originality}

This study is important to study the abundance and the interaction of the rhinoceros beetle in oil palm and coconut palm. The abundance of male and female of rhinoceros beetle were observed and the interaction between the population dynamic, different types of crop and different plant variety in each crop also evaluated. Our findings are an attempt to provide adequate knowledge in recommending potential farmers to select the best variety, which is more resistant to Oryctes Rhinoceros attacks.

DOI: 10.18488/journal.1005/2020.10.1/1005.1.56.67

ISSN (P): 2304-1455/ISSN (E):2224-4433

How to cite: Izaitul Aida, I., Mohd Rasdi, Z., Ismail, R., Ismeazilla, M. B., Mohd Faizol, K., Muhammad Shakir, Z., Nur Fakriyah, A. and Noor Shuhaina, S. M. (2020). Susceptibility and resistant of different host varieties of oil palm and coconut palm towards pest, rhinoceros beetle (Oryctes rhinoceros). Asian Journal of Agriculture and Rural Development, 10(1), 56-67.

(C) 2020 Asian Economic and Social Society. All rights reserved. 


\section{INTRODUCTION}

This study was conducted at Ladang Penyelidikan Segamat, Bukit Bujang, Segamat, Johor in Malaysia on the crucial effects of population dynamics of Oryctes Rhinoceros, particularly on host plants, oil palms and coconut palms, belonging to a similar family (palmae) with high risk infestation of the pest, which causes yield losses up to more than $50 \%$ in the plantation of oil palms. The control of this insect pest in oil palm plantation is becoming more challenging day-by-day, because ability of Oryctes Rhinoceros possesses high adaptability to and much tolerance with chemicals. Therefore, planting both crops could be high risk infestation; however, different varieties from both types of host plants could possibly influence the population of Oryctes Rhinoceros, and acts as a major Coleopteran pest in oil palm and coconut palm industries in Malaysia (Manjeri et al., 2014).

Information on the effects of different types of crops and plant host varieties is rather lacking. As the plants grow, plantation gradually becomes within more favorable environmental conditions for pests population. The types of crops and their varieties may consist of different nutrients and different plant traits such as, its physical and physiological appearance that may incline towards attracting the Oryctes Rhinoceros population. This study was also conducted to find the effects of plant host varieties and the sampling week towards population dynamics of Oryctes Rhinoceros. Moreover, our information would enable us to understand the effects of plant host varieties towards its population dynamics. Two types of host plants with their different varieties which are highly preferred by Oryctes rhinoceros were chosen in this study, such as oil palms and coconut palms. For the first host plant, a total area of oil palm included in this study was almost 20 hectares and varieties of the planting material used were D (Dura), X P (Pisifera) on commercial basis. All varieties of the planting material were planted randomly in the year 2013.

The African oil palms belong to an Elaeis Guineensis species, and the name 'guineensis' refers to the area's name, Guinea. Elaeis Guineensis originated in tropical Africa but currently planted in Malaysia. Regions falling in Asia and Pacific, Central and South America, and Africa could be grouped into three categories of countries that contribute in plantation of oil palms. The Malaysian oil palms industry was established in 1911. Since oil palm is one of the main crops that develop most rapidly in the world, Malaysia's oil palms industry contributed RM49.6 billion as net income during the year 2009. Currently Indonesia stands as the largest oil palms planted country, covering an area of 7.825 million ha, whereas Malaysia is the second largest planter of oil palms within an area of 4.853 million ha (Abdullah, 2011).

It has been frequently observed that oil palms plantations face major acute problems in terms of pests and plant diseases occurrence. Many researches were undertaken besides studying adequate technologies with attempts to solve the pest problems. The most critical and serious threats faced by the farmers come from the attacks from various insect pests, such as bag-worms, rhinoceros beetles, etc., which are the causes of the losses in oil palms yield. Initially the coconut palms are usually planted in smaller scales by farmers and/or individuals, which gradually turn into larger scale plantations. Until 2011, more than 80,000 farmers planted coconut palms. In the same year, data from Malaysian Department of Agriculture (known as Jabatan Pertanian Malaysia) showed that from within the total percentage and total hectare of coconut palms planted, only $2 \%$ belonged to Plantation Companies, covering just 1717 hectares, whereas remaining 98\% was planted by farmers and/or individuals on a wide area of 107,111 ha. Its huge plantation makes the coconut palms to stand at fourth position among crops, after oil palms, rubber and paddy. Also being called traditional crops in Malaysia, the coconut palms are usually planted by individuals in small scales only. Moreover, the coconut palms industry is considered to be an important economic source of Malaysia. 
Malayan Yellow Dwarf (MYD), Malayan Red Dwarf (MRD) and Tagnanan or matag were selected as main varieties to evaluate the population of Oryctes rhinoceros in this study. Since MYD and MRD are originally taken as principle source of female for matag and Tagnanan, the main source of male tend to be contributing in pollination process. Therefore, when MRD/MYD cross with Tagnanan, Matag will be automatically produced so as to prove highly valuable as compared to other varieties, because of its coconut characteristics (DOA, 2012). The copra (coconut) has more thickness and the size of the fruit is apparently bigger than that of "Pandan" and "Gading". The physical properties of coconut palms for each and every variety are different. Based on its physical appearance, the colors of palms also seem to be different. The color of coconut palms and its fruit are the main characteristics of indicators so as to show appropriate identity of the varieties. The stem and leaves of MYD palms are yellowish in color, whereas MRD seems to be more likely as orange, and Tagnanan are almost greenish. Physically, the height (about 15 to 18 meters) of Tagnanan palms (also known as Malayan Tall) is taller as compared to MYD and MRD varieties, with average height of 6 meters and usually termed as ' $d$ warf' varieties.

The main objective of this study was, as mentioned earlier, to evaluate the abundance and population dynamics of the rhinoceros beetles in both crops of oil palms and coconut palms with effective significance of different plant varieties towards the pest in both types of crops for the whole sampling period. The study also attempts to evaluate the interaction and relationship between rhinoceros beetle and both crops of oil palms and coconut palms, along with a variety of coconut palms, namely Malayan Yellow Dwarf (MYD), Malayan Red Dwarf (MRD) and Tagnanan. MYD and MRD were taken as female source of Matag and Tagnanan was the male source of Matag.

\section{MATERIAL AND METHODS}

\subsection{Trapping system}

The population and abundance of Oryctes rhinoceros were observed and caught by using traps. Pheromone trap was used in this study to catch Oryctes rhinoceros to evaluate the population and abundance of Oryctes rhinoceros for one year sampling period in both host plants such oil palm and coconut palm. The number of Oryctes rhinoceros beetle were counted and recorded.

\subsection{Pheromone trap (Oryctes rhinoceros)}

Pheromone traps was used in oil palm plantation to control Oryctes rhinoceros population. Pheromone trap become an important component in IPM for controlling and monitoring Oryctes rhinoceros in oil palm plantation. This trapping also can be used to study the ecological of Oryctes rhinoceros. In this study, pheromone trap was used to collect adult male of Oryctes rhinoceros. Ethyl 4-methyloctanote is a pheromone aggregation which is produced for commercial used (Hallet et al., 1995). Chung (1997) claimed that the double vane type of pheromone trap was found to be the most effective and economical. In this study, double vanes trapping were used and placed at 3 meters above ground, and for young oil palm was 1-2 meters above the canopy. The pheromone was hung in the center of metal vanes. The metal vanes like a zinc plate were placed on top of the pails. One unit of pheromone trap was installed for every 2 hectares and replaced a new hormone set for every two months.

The numbers female and male of Oryctes rhinoceros were recorded in this study. The number of the Oryctes rhinoceros was collected and counted from the pheromone trap that hanged at the boundaries of the oil palm experimental plot. The height of trap and distance between the pheromone trap was following the standard of procedure in Ladang Penyelidikan Bukit Bujang. FELDA and others plantation also used the same technique. High consideration on the elevation of traps on the top of the pole is crucial before hanging the pheromone trap. It is because the Oryctes rhinoceros is significantly attracted to the pheromone trap. Therefore, setting up optimum elevation of pheromone trap's pole and the distance interval between pheromone traps which was 125 meters from one to another, maximum number of rhinoceros can be caught. 


\subsection{Background of study area}

The experiments in this study were carried out in the field at Ladang Penyelidikan Bukit Bujang, Segamat, Johor, Malaysia. The oil palm and coconut palm of research plots were planted in 2013. The palms planting distance for oil palm and coconut palms were designed with $29 \mathrm{~m} \times 29 \mathrm{~m}$ between palms except for variety MYD and MRD was $22 \mathrm{~m}$ x $22 \mathrm{~m}$ between palms respectively. To study rhinoceros population on the both host palm plants, the selected experimental plots separately were chosen and consisted of two types of palms namely oil palm and coconut palm with several varieties for each type of palms as a key factor that influenced the population and abundance of Oryctes rhinoceros. There were two main factors influenced rhinoceros population that was according to firstly the types of varieties of each types of palm against rhinoceros population and secondly the time of sampling period for the whole year. For the first factor, the populations of Oryctes rhinoceros were observed in two varieties of oil palm and three varieties of coconut palm. The number of rhinoceros was observed by using pheromone trap and was replicated five times for each plot varieties respectively for oil palm as a host plant. The variety was DXP PPNJ 1 which labeled as OP1R1, OP1R2, OP1R3, OP1R4, and OP1R5 and for variety DXP PPNJ 2 labeled as OP2R1, OP2R2, OP2R3, OP2R4, and OP2R5.

The experimental plots for the coconut palm consisted of three varieties as the second factor of host plant. For the second host plant, there were three varieties of coconut palms namely for Malayan Yellow Dwarf (MYD) palm variety with three replicates such as CP1R1, CP1R2 and CP1R3; for Malayan Red Dwarf (MRD) palm variety with three replicates such as CP2R1, CP2R2, and CP2R3; and for Tagnanan (T) palm variety with also three replicates such as CP3R1, CP3R2 and CP3R3. The number of rhinoceros was observed by using pheromone trap for each plot varieties respectively for coconut palm as host plant. Each experimental plot of host plant was planted in 6 hectares for each variety and the total acreage for coconut palm was 18 hectares. The observation on the rhinoceros population was designed by placing the pheromone traps in the particular plots as common practice done by FELDA. The total size of land for the selected experimental plot was 20 hectares.

\subsection{Preparation of trapping system}

There was two (2) types of traps were installed which was pheromone trap and yellow sticky trap. Pheromone trap and yellow sticky traps was installed at each block's boundaries in each experimental plot according to the standard practice. For pheromone traps, the height of the traps is one feet higher than the oil palm tree. Height of the trapping was 7-8 feet from the ground. Pheromone trap was hung at the top of pole. Every 2 months the pheromone was replaced with the new one. The pail was hung below the vane and pheromone purposely to collect the Oryctes rhinoceros. Yellow sticky trap was installed 1 meter apart from the pheromone trap. The yellow sticky trap was replaced for every two weeks.

\subsection{Parameters of study}

Number of Oryctes rhinoceros male and female was recorded. All the data were collected and monitored biweekly. The pheromones were replaced for every two months to ensure the accuracy and reliability of data.

\subsection{Data collection}

The trapped Oryctes rhinoceros were taken and recorded for every two weeks after pheromone and yellow sticky trap installation. In oil palm and coconut palm field study, there were five (5) plots and each plot consisted of five and three replications for pheromone traps and yellow sticky trap respectively. Each replication has one pheromone trap and one yellow sticky trap. Each replication, number of the male and female of Oryctes rhinoceros was counted.

For pheromone trap, the numbers of Oryctes rhinoceros were collected including male and female. For yellow sticky trap, the number of parasitoids was also collected and recorded. The data was 
collected to determine the population dynamic of Oryctes rhinoceros and parasitoid. The number of Oryctes rhinoceros and parasitoid was recorded and sorted in order to determine the abundance of the population and also to differentiate the population between host plants, oil palm and coconut palm. The Oryctes rhinoceros were attracted to the pheromones and entered and trapped in the trap. Male and female Oryctes rhinoceros were trapped because pheromones used in this study was not in specific sexual. In this study, pheromone traps were placed randomly in each block. The maintenance and agronomy practices in Ladang Penyelidikan Bukit Bujang were done as planned in schedule and followed the standard of procedure.

\subsection{Data analysis}

All the data from the field were collected and recorded. Using statistical software the data is being imported from MS Excel. By using descriptive statistic, means of Oryctes rhinoceros's population and standard error was also measured. In host plant of oil palm and coconut palm, data population dynamic of male, female and total (male and female) of Oryctes rhinoceros in OP1, OP2, MRD, MYD and Tagnanan were analyzed. In this study, two factors were analyzed. There were two factors of crops were analyzed namely oil palm and coconut palm. Independent t-test was used to analyze the influence of two varieties of oil palms plots towards Oryctes rhinoceros and Two-ways ANOVA were used to analyze the effect of three varieties of coconut palms plots against Oryctes rhinoceros. Again, Independent t-test and One-way ANOVA were used to analyze the effect of the sampling week towards population dynamic of the Oryctes rhinoceros in oil palm and coconut palm respectively.

\section{RESULTS}

\subsection{Population dynamic and abundance of oryctes rhinoceros in oil palm and coconut palm}

\subsubsection{Oil Palm}

In this study, population dynamic of total male and female of Oryctes rhinoceros in oil palm was significant difference $(\mathrm{P}<0.05 ; \mathrm{t}=2.912 ; \mathrm{df}=198)$ for the whole sampling period (See Table 1$)$. The population dynamic of Oryctes rhinoceros male was fluctuated over the sampling periods from Week 2 till Week 40 in oil palm plots. The highest number of male was observed in Week 16 $(16.20 \pm 3.62)$ and the lowest number $(0)$ in Week 34 . At early sampling period to the middle sampling period, the number of Oryctes rhinoceros was increasing and fluctuating consistently in number ranging from 10 to 16 units but fluctuated in the middle of sampling period. However, the numbers of beetle decreasing gradually at the end of sampling period.

For the female of Oryctes rhinoceros in the oil palm, the population of Oryctes rhinoceros was also found to be fluctuated through the sampling periods. The highest mean number of female was recorded in Week $36(13.60 \pm 2.09)$ and the lowest number $(0.60 \pm 0.60)$ was in Week 34 . The population was higher at early and at the end of sampling period, interestingly the female of Oryctes rhinoceros were consistently presence in the oil palm for the whole sampling periods. In week 20, means number for both Oryctes rhinoceros male and female were quite similar wtih 4.40 \pm 1.36 and $4.40 \pm 1.75$ respectively.

Interestingly, both male and female of Oryctes rhinoceros were found similar trend with the lowest number at Week 34 but different week for the male. Overall, the presence of male and female were consistent in oil palm for the entire sampling period ranging from 1 to 15 . In general, the mean number of Oryctes rhinoceros for total (male and female) was fluctuated for the whole sampling period. 
Table 1: Comparison (t-test) on the population of Oryctes rhinoceros in different plant varieties (oil palm) for the whole sampling period (weeks 2-40)

\begin{tabular}{cccccccccc}
\hline $\begin{array}{l}\text { No. of } \\
\text { Weeks }\end{array}$ & & Male & & \multicolumn{3}{c}{ Female } & & \multicolumn{2}{c}{ Total (Male \& Female) } \\
\hline & t-value & d.f & P< & t-value & d.f & P< & t-value & d.f & P< \\
\hline 2 & 0.949 & 8 & 0.05 & -0.602 & 8 & 0.05 & 0.308 & 8 & 0.05 \\
4 & 0.724 & 8 & 0.05 & 0.480 & 8 & 0.05 & 0.772 & 8 & 0.05 \\
6 & 0.841 & 8 & 0.05 & 1.183 & 8 & 0.05 & 0.921 & 8 & 0.05 \\
8 & 0.828 & 8 & 0.05 & 1.023 & 8 & 0.05 & 0.903 & 8 & 0.05 \\
10 & -0.814 & 8 & 0.05 & 1.187 & 8 & 0.05 & 0.137 & 8 & 0.05 \\
12 & 1.309 & 8 & 0.05 & 1.614 & 8 & 0.05 & 1.878 & 8 & 0.05 \\
14 & 0.435 & 8 & 0.05 & 0.730 & 8 & 0.05 & 0.572 & 8 & 0.05 \\
16 & 0.188 & 8 & 0.05 & 1.756 & 8 & 0.05 & 0.618 & 8 & 0.05 \\
18 & 0.363 & 8 & 0.05 & 1.577 & 8 & 0.05 & 0.912 & 8 & 0.05 \\
20 & 0.00 & 8 & 0.05 & -0.470 & 8 & 0.05 & -0.288 & 8 & 0.05 \\
22 & -2.105 & 8 & 0.05 & -0.147 & 8 & 0.05 & -1.320 & 8 & 0.05 \\
24 & -0.258 & 8 & 0.05 & 0.894 & 8 & 0.05 & 1.134 & 8 & 0.05 \\
26 & 0.759 & 8 & 0.05 & -0.506 & 8 & 0.05 & 0.197 & 8 & 0.05 \\
28 & 1.140 & 8 & 0.05 & -0.100 & 8 & 0.05 & 0.555 & 8 & 0.05 \\
30 & 0.967 & 8 & 0.05 & -0.209 & 8 & 0.05 & 0.717 & 8 & 0.05 \\
32 & 1.453 & 8 & 0.05 & 0.773 & 8 & 0.05 & 1.211 & 8 & 0.05 \\
34 & 1.00 & 8 & 0.05 & 0.00 & 8 & 0.05 & 1.00 & 8 & 0.05 \\
36 & 0.125 & 8 & 0.05 & 1.209 & 8 & 0.05 & 0.923 & 8 & 0.05 \\
38 & 0.224 & 8 & 0.05 & 0.695 & 8 & 0.05 & 0.616 & 8 & 0.05 \\
40 & 2.626 & 8 & 0.05 & 2.277 & 8 & 0.05 & 2.670 & 8 & 0.05 \\
T-Test & $\mathrm{t}$ & $\mathrm{df}$ & $\mathrm{P}$ & $\mathrm{t}$ & $\mathrm{df}$ & $\mathrm{P}$ & $\mathrm{t}$ & $\mathrm{df}$ & $\mathrm{P}$ \\
& 2.023 & 198 & $<0.05$ & 2.976 & 198 & $<0.05$ & 2.912 & 198 & $<0.05$ \\
\hline
\end{tabular}

\subsubsection{Coconut palm}

The population dynamic of Oryctes rhinoceros for male was fluctuated through the week. There was significant difference $(\mathrm{P}<0.05 ; \mathrm{df}=19,180 ; \mathrm{F}=2.421)$ in mean number of male Oryctes rhinoceros for the whole sampling period. The highest number of male $(23.33 \pm 7.31)$ was found in week 4 and the lowest number $(1.33 \pm 0.67)$ in week 28 . Population Oryctes rhinoceros male in week 18 until week 28 not much differ through the week. The means number of male of Oryctes rhinoceros from $1.00-5.00$ units. In week $18(4.00 \pm 1.15)$ till week $22(4.67 \pm 1.76)$, the population Oryctes rhinoceros male increased gradually and started to decrease in week 24 (3.67 \pm $0.67)$ till week $28(1.33 \pm 0.67)$.

Generally, the population dynamic of Oryctes rhinoceros for female was fluctuated through the week. There was also significant difference $(\mathrm{P}<0.05 ; \mathrm{df}=19,180 ; \mathrm{F}=5.959)$ in mean number of female Oryctes rhinoceros for the whole sampling period. Interestingly, the highest number of female $(21.00 \pm 6.81)$ was recorded in week 38 and the lowest number $(2.00 \pm 0.58)$ in week 26 . For the entire sampling period, similar trend was observed on the population dynamic of Oryctes rhinoceros for the total male and female was fluctuated. The number total (male and female) of Oryctes rhinoceros was found significantly difference $(\mathrm{P}<0.05 ; \mathrm{df}=19,180 ; \mathrm{F}=3.249)$ for the whole sampling week. The highest number of Oryctes rhinoceros $(36.00 \pm 9.24)$ for total male and female was observed in week 4 and the lowest number $(4.33 \pm 3.84)$ was found in week 34 . Interestingly, this study found that in week 6 , week 38 and week 40 population male and female greatly differ. In week $6($ male $=19.33$, female $=6.67)$, week $38($ male $=8.00$, female $=21.00)$ and week $40($ male $=4.33$, female $=17.00)$. 


\subsection{Effect of the plant variety and sampling week towards oryctes rhinoceros in oil palm and coconut palm}

\subsubsection{Oil palm}

In general, the infestation of Oryctes rhinoceros male on oil palm did not vary very much in two experimental plots of oil palm. However, the plant varieties have an effect towards population of Oryctes rhinoceros male attack to the oil palm. There was significantly difference $(\mathrm{t}=2.023, \mathrm{P}<$ 0.05 ) in the population of Oryctes rhinoceros male in oil palm.

The population Oryctes rhinoceros female in oil palm plots also were studied. Again, population of female Oryctes rhinoceros was found to be significantly difference $(\mathrm{t}=2.976, \mathrm{P}<0.05)$ in mean number due to oil palm varieties. Plant varieties namely DXP PPNJ 1 and DXP PPNJ 2 oil palm were able to give effect to the population of Oryctes rhinoceros female significantly. DXP PPNJ 1 and DXP PPNJ 2 have an effect towards the population of the male and female Oryctes rhinoceros.

For the total male and female population of Oryctes rhinoceros, interestingly, this study found that the plant variety of oil palm DXP was found significantly affected $(\mathrm{t}=2.912, \mathrm{P}<0.05)$ towards mean number of Oryctes rhinoceros male and female. It was probably due to the differences of plant varieties could have different chemical compounds and properties and different morphology attracting the Oryctes rhinoceros.

Data plant varieties in oil palm (DXP PPNJ 1 and DXP PPNJ 2) and number of Oryctes rhinoceros male, female and total (male and female) between sampling weeks from week 2 till week 40 was recorded and analyzed. Interestingly, this studies was found that there was no effect of the sampling week towards population of Oryctes rhinoceros male $(\mathrm{P}>0.05)$, female $(\mathrm{P}>0.05)$ and total (male and female $)(\mathrm{P}>0.05)$ in oil palm in week 2 till week 38. Meanwhile, in weeks 40, sampling weeks give an effect towards population Oryctes rhinoceros male and total (male and female) $(\mathrm{P}<0.05)$. The highest and the lowest mean number population of male of Oryctes rhinoceros were recorded in week $16(16.20 \pm 3.62)$ and week $34(0)$, meanwhile, sampling week for week 16 and 34 was observed no significant effect $(\mathrm{P}>0.05)$ towards the population of the male of Oryctes rhinoceros in oil palm. The highest and the lowest mean number of the population of female Oryctes rhinoceros was in week $36(13.60 \pm 2.09)$ and week $34(0.60 \pm 0.60)$ in oil palm and subsequently there was no significant effect $(\mathrm{P}>0.05)$ of the sampling week towards the population of the female Oryctes rhinoceros in week 36 and 34.

There was significantly difference $(\mathrm{P}<0.05)$ in population of male, female and total (male and female) of Oryctes rhinoceros in oil palm. Meanwhile, this study found that sampling weeks did not give significant effects $(\mathrm{P}>0.05)$ but plant variety gave effect towards the population of Oryctes rhinoceros in oil palm.

\subsubsection{Coconut palm}

In this study, the number of Oryctes rhinoceros male, female and total (male and female) in each plot of coconut palm with different plant variety was studied. The population of Oryctes rhinoceros male was recorded significantly difference $(\mathrm{F}=6.888 ; \mathrm{df}=2,180 ; \mathrm{P}<0.05)$ in among plant varieties of coconut palm. The abundances of male Oryctes rhinoceros were affected significantly by varieties of coconut palm.

Generally, the plant varieties in coconut palm gave an effect towards the population of Oryctes rhinoceros male. This study revealed that the plant variety could give significant effect to the population of the Oryctes rhinoceros male in coconut palm. The population of Oryctes rhinoceros was found higher significantly $(\mathrm{P}<0.05)$ in MYD variety as compared to MRD and Tagnanan. However, MRD and Tagnanan had no significant difference $(\mathrm{P}>0.05)$ in the population of Oryctes rhinoceros male in coconut palm. From the data collected and recorded in field, the total number 
Oryctes rhinoceros captured in the experimental plot MYD was 263 beetles compared to MRD and Tagnanan with 137 and 106 beetles respectively. During the observation in the field, MYD variety was severely attacked by Oryctes rhinoceros compared to MRD and Tagnanan. Probably, the population of Oryctes rhinoceros could influence by physical appearances particularly the color of the plants. For the MYD palm, stem and fruits was yellow in color, MRD was orange in color and Tagnanan was greenish in color. This color may attract the Oryctes rhinoceros which parallel with the study done by Mohammed and Hassan (2004) indicated that beetle highly preferred with the yellow color.

Result showed the effect of the plant variety towards Oryctes rhinoceros female in coconut palm. The population Oryctes rhinoceros female was significantly different $(\mathrm{F}=9.767 ; \mathrm{df}=2 ; \mathrm{P}<0.01)$ in different plant varieties of coconut palm.

Oryctes rhinoceros was found to be highest means in MYD to Tagnanan and MRD. The mean number of Oryctes rhinoceros female in Tagnanan $($ mean $=1.80)$ and MRD (mean $=2.20)$ seemed to be lower than number of female in MYD (mean $=4.15)$.

Based on the observation and data collection in coconut palm field during the study, the number of Oryctes rhinoceros female more found caught in the pheromone trap in plant variety MYD. The number of the female in MYD was 249 units followed by MRD with 132 and Tagnanan with 108 units. Female more attracted to plant variety MYD palm compared to MRD and Tagnanan probably because of the pant trait such as color physical appearance of the plant variety itself. Physical color of the palm is yellow. Yellow is bright colors which make the Oryctes rhinoceros more attracted to the variety compared to others plant varieties. MRD is golden in color and Tagnanan is greenish in color (DOA, 2012).

Total mean number of Oryctes rhinoceros (male and female) was significantly difference $(\mathrm{P}<0.05)$ in different plant varieties of coconut palm. The plant varieties in coconut palm plots gave effect towards total male and female population of Oryctes rhinoceros $(\mathrm{P}<0.05 ; \mathrm{df}=2,180 ; \mathrm{F}=11.273)$ (see Table 2).

Table 2: Two-ways analysis of variance and the population of oryctes rhinoceros in three different varieties of coconut palm for the whole sampling period (Week 2 - Week 40)

\begin{tabular}{lccccccccc}
\hline $\begin{array}{l}\text { No. of } \\
\text { Weeks }\end{array}$ & \multicolumn{3}{c}{ Male } & \multicolumn{3}{c}{ Female } & \multicolumn{3}{c}{ Total (Male \& Female) } \\
\hline & F-value & d.f & P> & F-value & d.f & P> & F-value & d.f & P> \\
\hline 2 & 1.419 & 2 & 0.05 & 1.800 & 2 & 0.05 & 4.636 & 2 & 0.05 \\
4 & 1.103 & 2 & 0.05 & 2.487 & 2 & 0.05 & 1.536 & 2 & 0.05 \\
6 & 0.682 & 2 & 0.05 & 0.929 & 2 & 0.05 & 0.721 & 2 & 0.05 \\
8 & 0.198 & 2 & 0.05 & 0.173 & 2 & 0.05 & 0.173 & 2 & 0.05 \\
10 & 1.125 & 2 & 0.05 & 0.247 & 2 & 0.05 & 0.120 & 2 & 0.05 \\
12 & 3.011 & 2 & 0.05 & 1.300 & 2 & 0.05 & 2.600 & 2 & 0.05 \\
14 & 2.767 & 2 & 0.05 & 2.116 & 2 & 0.05 & 2.525 & 2 & 0.05 \\
16 & 3.106 & 2 & 0.05 & 11.21 & 2 & 0.05 & 5.099 & 2 & 0.05 \\
18 & 2.400 & 2 & 0.05 & 2.850 & 2 & 0.05 & 2.423 & 2 & 0.05 \\
20 & 1.867 & 2 & 0.05 & 1.462 & 2 & 0.05 & 1.370 & 2 & 0.05 \\
22 & 1.550 & 2 & 0.05 & 0.765 & 2 & 0.05 & 2.400 & 2 & 0.05 \\
24 & 0.125 & 2 & 0.05 & 0.722 & 2 & 0.05 & 1.000 & 2 & 0.05 \\
26 & 1.444 & 2 & 0.05 & 0.273 & 2 & 0.05 & 0.650 & 2 & 0.05 \\
28 & 0.167 & 2 & 0.05 & 0.143 & 2 & 0.05 & 0.083 & 2 & 0.05 \\
30 & 0.024 & 2 & 0.05 & 0.034 & 2 & 0.05 & 0.086 & 2 & 0.05 \\
32 & 6.050 & 2 & 0.05 & 1.811 & 2 & 0.05 & 5.688 & 2 & 0.05 \\
\hline
\end{tabular}




\begin{tabular}{lccccccccc}
\hline 34 & 1.00 & 2 & 0.05 & 0.860 & 2 & 0.05 & 0.917 & 2 & 0.05 \\
36 & 4.269 & 2 & 0.05 & 11.224 & 2 & 0.05 & $\mathrm{~F}=15.183$ & 2 & 0.05 \\
38 & 0.054 & 2 & 0.05 & 2.571 & 2 & 0.05 & $\mathrm{~F}=1.419$ & 2 & 0.05 \\
40 & 2.333 & 2 & 0.05 & 3.167 & 2 & 0.05 & $\mathrm{~F}=2.827$ & 2 & 0.05 \\
\hline
\end{tabular}

There was significant difference $(\mathrm{P}<0.05)$ on the population (total of male and female) of Oryctes rhinoceros among the plant varieties of MYD, MRD and Tagnanan coconut palm.

The means number of the total male and female of Oryctes rhinoceros in each plant varieties. The number of Oryctes rhinoceros was found significant higher in MYD (8.53) as compared to plant variety MRD (4.48) and Tagnanan (3.57). From the result, it can be concluded that plant varieties particularly Tagnanan and MRD seemed less attracted Oryctes rhinoceros rather than plant variety MYD.

Table 3 shows the population of the Oryctes rhinoceros in three plant varieties namely MYD, MRD and Tagnanan. Plant varieties gave effect towards to the total of Oryctes rhinoceros male and female $(\mathrm{P}<0.05 ; \mathrm{df}=2,180 ; \mathrm{F}=13.921)$ in coconut palm.

From the analysis, sampling week did also give significant effect $(\mathrm{P}<0.05 ; \mathrm{df}=19,180 ; \mathrm{F}=3.249)$ towards the total population of male and female of Oryctes rhinoceros. Both treatment and sampling week showed that there were significantly differences in mean of total number of Oryctes rhinoceros male and female. Meanwhile, there was no significant interaction $(\mathrm{P}>0.05$; $\mathrm{df}=$ 38,$180 ; \mathrm{F}=0.970$ ) between treatment (plant variety) and sampling week. The differences of mean number of Oryctes rhinoceros in three selected varieties was observed with mean square (error) $=$ 30.106. Plant variety for coconut palm, MYD, MRD and Tagnanan had influenced the total population of male and female of Oryctes rhinoceros.

Table 3: Results of two-way ANOVA

\begin{tabular}{lccc}
\hline Two - Ways Anova & Male & Female & $\begin{array}{c}\text { Total (Male } \& \\
\text { Female) }\end{array}$ \\
\hline \multirow{3}{*}{ Variety } & $\mathrm{F}=7.576$, & $\mathrm{F}=16.369$, & $\mathrm{F}=13.921$, \\
& $\mathrm{df}=2,180$, & $\mathrm{df}=2,180$, & $\mathrm{df}=2,180$, \\
& $\mathrm{P}>0.05$ & $\mathrm{P}<0.01$ & $\mathrm{P}<0.01$ \\
Sampling Week & $\mathrm{F}=2.421$, & $\mathrm{F}=5.959$, & $\mathrm{F}=3.249$, \\
& $\mathrm{df}=19,180$, & $\mathrm{df}=19,180$, & $\mathrm{df}=19,180$, \\
Variety X Sampling Week & $\mathrm{P}<0.05$ & $\mathrm{P}<0.01$ & $\mathrm{P}<0.01$ \\
& $\mathrm{~F}=0.755$, & $\mathrm{F}=1.669$, & $\mathrm{F}=0.970$, \\
& $\mathrm{df}=38,180$, & $\mathrm{df}=38,180$, & $\mathrm{df}=38,180$, \\
& $\mathrm{P}>0.05$ & $\mathrm{P}>0.05$ & $\mathrm{P}>0.05$ \\
\hline
\end{tabular}

This phenomenon happened probably due to the different characteristic of the plant variety. MYD and MRD had different in color and the outer layer of MYD was reddish in color, MYD was yellowish color and Tagnanan was greenish in color. The color of coconut could influence and attracts the Oryctes rhinoceros. The color also may have relationship with the nutrient content and secondary metabolites. The nutrient contents and secondary metabolites need to be studied to get better result for the next finding.

The lowest means number of total male and female of Oryctes rhinoceros among sampling week in coconut palm was recorded in week 34 (mean $=1.44$ ). The population of Oryctes rhinoceros in week 4 was found significantly difference $(\mathrm{P}<0.05)$ compared to week 20,24,26,28 and 34 . At week 4 (mean $=12.00)$ total number of Oryctes rhinoceros male and female was observed to be the highest in number when compared to other weeks of sampling. Total number male and female of Oryctes rhinoceros in week 4 was 108 beetles compared to week 34 was only 13 beetles. 
Oryctes rhinoceros male in coconut palm have a significant difference $(\mathrm{P}<0.05 ; \mathrm{df}=2,180 ; \mathrm{F}=$ 7.576) between treatment (plant variety) and sampling week $(\mathrm{P}<0.05 ; \mathrm{df}=19,180 ; \mathrm{F}=2.421)$. However, the plant varieties in coconut palm and sampling week had no significant interaction with population Oryctes rhinoceros male in coconut palm plots. R-Squared value is 0.428 . Figure 4 shows the means for groups in homogeneous subset with total number of Oryctes rhinoceros male between sampling week. The lowest mean number of Oryctes rhinoceros was recorded in week 28 $($ mean $=0.44)$ and the highest was observed in week 4 (mean $=7.78)$. Sampling week in week 4 $($ mean $=7.78)$ was significantly difference $(\mathrm{P}<0.05)$ in mean number of between week 28 (mean $=$ $0.44), 34($ mean $=0.56)$, and week $26($ mean $=0.89)$.

Population Oryctes rhinoceros female in coconut palm was also studied between the sampling week and plant variety. Table 3 shows plant variety $(\mathrm{P}<0.05 ; \mathrm{df}=2,180 ; \mathrm{F}=16.369)$ and sampling week $(\mathrm{P}<0.05 ; \mathrm{df}=19,180 ; \mathrm{F}=5.959)$ gave effect significantly to the female population in coconut palm for the whole sampling period. In the meantime, there was no significant interaction $(\mathrm{P}>0.05 ; \mathrm{df}=38,180 ; \mathrm{F}=0.755)$ between plant variety and sampling week for Oryctes rhinoceros female population in coconut palm.

The total number of female of Oryctes rhinoceros was observed for their population dynamic in coconut palm over 20 sampling weeks. The population Oryctes rhinoceros female was fluctuating between the sampling weeks. The mean number of female had significant difference $(\mathrm{P}<0.05)$ among the coconut palm varieties and sampling weeks. Figure 5 shows the mean number female of Oryctes rhinoceros between sampling week. Lower number of female of Oryctes rhinoceros was observed in week $26(0.67)$ when compared to week 38 (mean $=7.00)$.

\section{DISCUSSION}

The effect of the plant host varieties and the sampling weeks towards population dynamics of Oryctes rhinoceros in oil palm and coconut palm were observed. Population of Oryctes rhinoceros were fluctuated for the whole sampling period due to some reasons. This could probably due to climatic factors, plant characteristics, compound in plant nutrients and others factors (Fathul et al., 2018).

In general, Oryctes rhinoceros male and female were found different in mean number between both varieties of oil palm and also affected by sampling date. Interestingly, this study found that plant variety in oil palm DXP gave an effect towards the population male, female and total (male and female) of Oryctes rhinoceros. It is probably due to different plant varieties have different chemical compounds inside the palm and different morphology that will attract the Oryctes rhinoceros differently. Norman (2001), found that Oryctes rhinoceros more found in the decomposed trunk heaps. Beetle also more attract to the volatile compounds produced by the decaying biomasses. Therefore, oil palm plant varieties could influence the population of the Oryctes rhinoceros because probably they are attracted to the $\mathrm{v}$ Zolatile $\mathrm{c}$ ompounds that presence in the oil palm itself. Morin et al. (1996) claimed that pheromone produced in male Oryctes rhinoceros to attract females with maturing eggs. $81 \%$ female Oryctes rhinoceros were attracted to the pheromone trap in Indonesia. Norman et al. (2007) were recorded that the average pheromone trap manages to catch female Oryctes rhinoceros is $60 \% .92 \%$ female Oryctes rhinoceros were gravid with 16 eggs and looking for breeding sites.

From another finding about different planting material, Ahmad (2006), claimed that planting material from Tissue Culture palms are higher mean percentage damaged caused by Oryctes rhinoceros compared to planting material DXP palms. In this study, oil palm DXP material was tested as a plant host variety in oil palm experimental plot. However, previous study mentioned that when palms more than three years old in all planting material, the incidences of Oryctes rhinoceros damage can be reduced. Ahmad (2006) reported that topographies such as roadside, border mature 
palms, hillside, hilltop and swamps and valley did not contribute and related to the level of damage by Oryctes rhinoceros.

In coconut palm test plot, Oryctes rhinoceros male $(\mathrm{P}<0.05)$, female $(\mathrm{P}<0.01)$ and total (male and female) had great significant difference between MYD, MRD and Tagnanan. Post Hoc test was conducted and found that male, female and total (male and female) Oryctes rhinoceros in MRD was greatly influenced the Oryctes rhinoceros population compared to MYD and Tagnanan. This is probably due to the physical appearances plant varieties of MYD is in yellow color, MRD in reddish or golden color and Tagnanan in greenish color and some in golden color. Oryctes rhinoceros more attracted to MYD which is yellow physical appearance compared to MRD and Tagnanan. Yellow sticky trap color attracted more insect pest compared to pink, green, and orange color (Mohammed and Hassan, 2004). Additionally, the composition of the chemical properties and nutrient elements probably differed among varieties. In china, they found that corn in different varieties have different chemical composition (Zhang et al., 2016). Chemical composition in the plant may attract the population of the Oryctes rhinoceros due to the availability of the energy in the plant varieties. Bamikole and Ikhatua (2009) found that oil palm varieties Dura, Oleifera and Tenera have different nutritive value and gave significant effect of the material palm press fibre, palm clyx and palm oil sludge in making of ruminant stock product. The nutritive ranking based on variety is Tenera, Dura and Oleifera. Cellulose, lignin and hemicelluloses that are containing in the plant cell are also different in each plant varieties. The secondary metabolites and chemical defence in plant was also differed among varieties.

Therefore, Oryctes rhinoceros was proven attacked on plant MYD variety compared to MRD and Tagnanan in this study. This is probably due to preference of the beetle which more attracted to yellow color of plants and fruits of coconut. Further study should be carried out for the population of the plant variety. Main caused Oryctes rhinoceros attract to the variety. Oryctes rhinoceros male were caught and trapped in the pheromone trap compared to female. This finding was contradicted with (Jayanth et al., 2009). Jayanth et al. (2009) was found that beetle trapped in coconut palm plantation in India is $68 \%$ females. 54\% Oryctes rhinoceros were virgin and $34 \%$ gravid. Meanwhile, the excessive supplied of nutrient will attract insect pest to the plants (Fathul et al., 2018). Nutrients play their roles in aiding through growths and insect's fecundity. The lack of the findings particularly Oryctes rhinoceros in plant varieties for coconut palm, therefore this research was conducted to study the effect of the plant varieties MYD, MRD and Tagnanan in coconut palm towards Oryctes rhinoceros.

\section{CONCLUSION AND RECOMMENDATIONS}

While considering the varieties of oil palms, DXP PPNJ 1 and DXP PPNJ 2 gives an effective stance towards the population of the Oryctes Rhinoceros male, female and total (male and female) aspects. In coconut palm fields, the population of male, female and total (male and female) of Oryctes Rhinoceros also had great significant differences in different plant varieties, such as MYD, MRD and Tagnanan. Moreover, Oryctes Rhinoceros was found in more abundance to attack specifically on the plant variety, MYD as compared to MRD and Tagnanan. This could most probably be due to different chemical compounds found inside the palm having different plant varieties and different morphology that attracts the Oryctes Rhinoceros in a different manner. Further studies should be carried out in terms of chemical compounds' componnent in both 'palmae' varieties, so as to determine the main reason(s) why Oryctes Rhinoceros is apparently more attracted to this variety. Our study could be made an obvious inference showing that MYD is more susceptible to Oryctes Rhinoceros, when it is compared with other varieties, such as MRD and Tagnanan. Therefore, varities like MRD and Tagnanan or Matag (which is cross variety) could be recommended to farmers. Instead of having higher yield the farmers face less chances of attacks by major pests, particularly Oryctes Rhinoceros, within the same time period. 


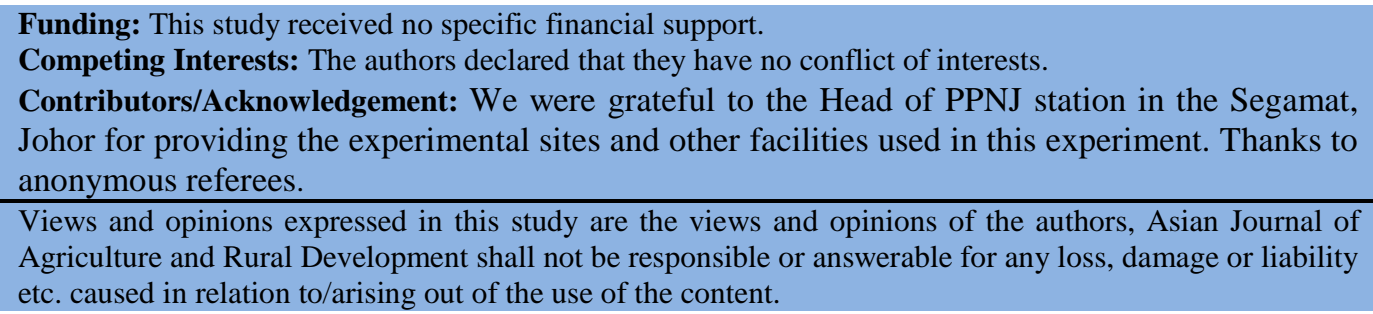

\section{References}

Abdullah, R.. (2011). World palm oil supply , demand , price and prospects: Focus on Malaysian and Indonesian palm oil industries. Oil Palm Industry Economic Journal, 11(2), 13-25.

Ahmad, A. H. (2006). Final report on control of rhinoceros beetle (Oryctes rhinoceros) (Scarabaeidae: Coleoptera) in Zero Burning Replanted Oil Palm Area. Felda Plantation, Lepar Utara, Pahang (2003-2006), pp. 1-71.

Bamikole, M. A., \& Ikhatua, U. J. (2009). Variety diversity effect on the chemical composition and dry matter degradation characteristic of residue and by-product of oil palm fruits. Animal Science Journal, 80(3), 239-249. doi.org/10.1111/j.1740-0929.2009.00630.x.

Chung, G. F. (1997). The bioefficacy of the aggregation pheromone in mass trapping of oryctes rhinoceros (L) in Malysia. The Planter, 73(852), 119-127.

DOA-Department of Agriculture Malaysia (2012). The direction and prospects of the coconut industry in shaping the country's economy. (Ahmad, Z, personal communication).

Fathul, N. A. K., Mohd Rasdi, Z., \& Nur, F. H. H. (2018). Interaction between oryctes rhinoceros and leaves nutrient content in oil palm. Journal of Advances in Agriculture, 8(1), 1408-1414.

Hallet, R. H., Perez, A. L., Gries, G., Gries, R., Pierce, H. D., Yue, J., Oehlschlager, A. C., González, L. M., \& Borden, J. H. (1995). Aggregation pheromone of coconut rhinoceros beetle, Oryctes rhinoceros (L.)(Coleoptera: Scarabaeidae). Journal of Chemical Ecology, 21(10), 1549-1570.

Jayanth, K. P., Mathew, M. T., Narabenchi, G. B., \& Bahnu, K. R. M. (2009). Reproductive status oryctes rhinoceros females captured in aggregation pheromone trps. Indian Coconut Journal, $52,17-20$.

Manjeri, G., Muhamad, R., \& Tan, S. G. (2014). Oryctes rhinoceros Beetles, an Oil Palm Pest in Malaysia. Annual Research \& Review in Biology, 4(22), 3429-3439.

Mohammed, A. A., \& Hassan, A. A. (2004). Trapping efficiency of various colored traps for insects in cucumber crop under greenhouse conditions in riyadh, Saudi Arabia. Natural Resources and Environmental Research Institute. Pakistan Journal of Biological Science, 7(7), 12131216. doi.org/10.17660/actahortic.2006.710.53.

Morin, J. P., Rochat, D., Malosse, C., Lettere, M., Desmier De Chenon, R., Wibwo, H., \& Descoins, C. (1996). Ethyl 4-methyloctanoate, major component of Oryctes rhinoceros (L.) (Coleoptera, Dynastidae). Comptes rendus de l'Academie des sciences. Serie III, Sciences de la vie, 319(7), 595-602.

Norman, K., Mohd Basri, W., Ramle, M., \& Siti Ramlah, A. A. (2007). The effect of mortality and influence of pheromone trapping on the infestation of Oryctes rhinoceros in an oil palm plantation. Journal of Asia-Pacific Entomology, 10(3), 239-250.

Norman, K. (2001). Environmental studies and infestation of rhinoceros beetles. Oryctes rhinoceros (Linn.) (Coleoptera: Scarabaiedae) in the Plantation Ecosystem of Palm Oil. Ph.D. dissertation. Faculty of Science and Technology, National University of Malaysia. Bangi, Malaysia. $270 \mathrm{pp}$.

Zhang, L., Li, Y. K., Li, Z. C., Li., Q. F., Lyu, M. B., Li, D. F., \& Lai, C. H. (2016). The nutritive value in different varieties of corn planted in one location fed to growing pigs over three consecutive years. Asian-Australian Journal of Animal Sciences, 29(12), 1768-1773. doi.org/10.5713/ajas.16.0052. 